\title{
SHARP BOUNDS FOR THE TOADER-QI MEAN IN TERMS OF HARMONIC AND GEOMETRIC MEANS
}

\section{Wei-Mao Qian, XiaO-Hui Zhang And Yu-Ming Chu}

Abstract. In the article, we present the greatest values $\alpha$ and $\lambda$, and the least values $\beta$ and $\mu$ in $[0,1 / 2]$ such that the double inequalities

$$
\begin{gathered}
H[\alpha a+(1-\alpha) b, \alpha b+(1-\alpha) a]<T Q(a, b)<H[\beta a+(1-\beta) b, \beta b+(1-\beta) a], \\
G[\lambda a+(1-\lambda) b, \lambda b+(1-\lambda) a]<T Q(a, b)<G[\mu a+(1-\mu) b, \mu b+(1-\mu) a]
\end{gathered}
$$

hold for all $a, b>0$ with $a \neq b$, where $H(a, b)=2 a b /(a+b), G(a, b)=\sqrt{a b}$ and $T Q(a, b)=$ $\frac{2}{\pi} \int_{0}^{\pi / 2} a^{\cos ^{2} \theta} b^{\sin ^{2} \theta} d \theta$ are respectively the harmonic, geometric and Toader-Qi means of $a$ and $b$.

Mathematics subject classification (2010): 26E60, 33C10.

Keywords and phrases: Toader-Qi mean, harmonic mean, geometric mean, modified Bessel function.

\section{REFERENCES}

[1] GH. ToAder, Some mean values related to the arithmetic-geometric mean, J. Math. Anal. Appl., 1998, 218 (2), 358-368.

[2] F. QI, X.-T. SHI, F.-F. LIU AND ZH.-H. YANG, A double inequality for an integral mean in terms of the exponential and logarithmic means, DOI: 10.13140/RG.2.1.2353.6800, available online at http://www.researchgate.net/publication/278968439.

[3] ZH.-H. YANG, Some sharp inequalities for the Toader-Qi mean, arXiv:1507.05430 [math.CA], available online at http://lib-arxiv-008. serverfarm.cornell.edu/abs/1507.05430.

[4] M. Abramowitz AND I. A. STEgun, Handbook of Mathematical Functions with Formulas, Graphs, and Mathematical Tables, U. S. Government Printing Office, Washington, 1964.

[5] D. K. KaZARINofF, On Wallis' formula, Edinburgh Math. Notes, 1956, 1956 (40), 19-21.

[6] M. BIERNACKI AND J. KRZYŻ, On the monotonity of certain functionals in the theory of analytic functions, Ann. Univ. Mariae Curie-Skłodowska, Sect. A, 1955, 9, 135-147.

[7] ZH.-H. YANG, Y.-M. CHU AND M.-K. WANG, Monotonicity criterion for the quotient of power series with applications, J. Math. Anal. Appl., 2015, 428 (1): 587-604.

[8] G. Pólya And G. Szegő, Problems and Theorems in Analysis I, Springer-Verlag, Berlin, 1998. 